\title{
The effectiveness, suitability, and sustainability of non-pharmacological methods of managing pain in community- dwelling older adults: a systematic review
}

\author{
Shuk Kwan Tang ${ }^{1 *}$ D, Mimi Mun Yee Tse ${ }^{1}$, Sau Fong Leung ${ }^{1}$ and Theofanis Fotis ${ }^{2}$
}

\begin{abstract}
Background: Pain is common in older adults. To maintain their quality of life and promote healthy ageing in the community, it is important to lower their pain levels. Pharmacological pain management has been shown to be effective in older adults. However, as drugs can have various side effects, non-pharmacological pain management is preferred for community-dwelling older adults. This systematic review evaluates the effectiveness, suitability, and sustainability of non-pharmacological pain management interventions for community-dwelling older adults.

Methods: Five databases, namely, CINHAL, Journals@Ovid, Medline, Psyclnfo, and PubMed, were searched for articles. The criteria for inclusion were: full-text articles published in English from 2005 to February 2019 on randomized controlled trials, with chronic non-cancer pain as the primary outcome, in which pain was rated by intensity, using non-pharmacological interventions, and with participants over 65 years old, community-dwelling, and mentally competent. A quality appraisal using the Jadad Scale was conducted on the included articles.

Results: Ten articles were included. The mean age of the older adults was from 66.75 to 76 . The interventions covered were acupressure, acupuncture, guided imagery, qigong, periosteal stimulation, and Tai Chi. The pain intensities of the participants decreased after the implementation of the intervention. The net changes in pain intensity ranged from -3.13 to -0.65 on a zero to ten numeric rating scale, in which zero indicates no pain and ten represents the worst pain.
\end{abstract}

Conclusions: Non-pharmacological methods of managing pain were effective in lowering pain levels in community-dwelling older adults, and can be promoted widely in the community.

Keywords: Chronic pain, Aged, Older adults, Community-dwelling, Non-pharmacological interventions, Complementary therapy, Systematic review

\section{Background}

Pain is a common occurrence in humans, especially in those suffering from chronic illnesses. Trauma, injury, and illnesses can cause pain in older adults. According to the International Association for the Study of Pain, pain is 'an unpleasant and emotional experience associated with actual or potential tissue damage or described in terms of such damage' [1]. The prevalence of pain in

\footnotetext{
* Correspondence: skangel.tang@connect.polyu.hk

${ }^{1}$ School of Nursing, The Hong Kong Polytechnic University, Kowloon, Hong Kong

Full list of author information is available at the end of the article
}

community-dwelling older adults ranges from 25 to $50 \%$ $[2,3]$. Persistent pain in a person for 3 months or more is recognized as chronic pain [4]. Pain originates from the musculoskeletal system [5-8], and the most common sites of pain for older adults are the back, arms, hips, and legs [5].

The American Geriatric Society provides clinical practice guidelines and recommendations on how to manage persistent pain in older persons [9]. Pain management in older adults can be complex because of the interactions between diseases. The use of analgesics is the most common method of relieving pain in older adults because of

(c) The Author(s). 2019 Open Access This article is distributed under the terms of the Creative Commons Attribution 4.0 International License (http://creativecommons.org/licenses/by/4.0/), which permits unrestricted use, distribution, and reproduction in any medium, provided you give appropriate credit to the original author(s) and the source, provide a link to the Creative Commons license, and indicate if changes were made. The Creative Commons Public Domain Dedication waiver (http://creativecommons.org/publicdomain/zero/1.0/) applies to the data made available in this article, unless otherwise stated. 
its effectiveness. When analgesics are prescribed and adjusted, special consideration and warnings have to be given to older persons who might be susceptible to the adverse effects of the analgesics $[9,10]$. The following are some common adverse effects of analgesics. Gastrointestinal bleeding, oliguria, fluid retention, decreased excretion of sodium, renal failure, and prolonged bleeding can result from the use of non-steroidal antiinflammatory drugs. Delirium, constipation, nausea, pupil constriction, and respiratory distress are the most common adverse effects brought about by morphine [11, 12]. In addition, changes in body composition, advanced age, and comorbidities can affect the pharmacokinetics and pharmacodynamics of the analgesics. The physiological changes related to ageing can affect an individual's absorption, excretion, and response to the analgesics. The pain reduction effect can be less than expected [13].

To lower the chances of developing adverse effects from the analgesics and to improve pain control in older adults, it has been suggested that non-pharmacological interventions be used in combination with analgesics [9, 14]. Non-pharmacological interventions for pain management are 'a number of physical and psychologic treatment modalities that often require active participation' [9]. Examples of non-pharmacological interventions include exercise programmes and education programmes for patients and their caregivers $[9,14]$. Such interventions can build self-reliance and a sense of control over pain, and it is suggested that they are 'an integral part of the approach to the management of any persistent pain problem' [9]. Older adults accept pain as part of the ageing process and tend not to use medication to reduce pain levels $[9,15]$. Non-pharmacological interventions can thus be an alternative choice for older adults who fear the side effects of analgesics.

A pain assessment is simple to perform and is a reliable way of obtaining information about the pain condition of older adults, especially when the older adults self-report their pain condition [16, 17]. A pain assessment is 'a fundamental process' that should be conducted before and after an intervention [18]. Reducing the intensity of a person's pain can be a way of measuring the effect of the intervention on pain levels. It is also essential to evaluate the suitability and sustainability of an intervention. Suitability refers to 'the quality of being right or appropriate for a particular person, purpose or situation' [19]. It is often assessed by obtaining the perceptions and views of the targeted population on the interventions or assessment tools [20-22]. Sustainability is 'the ability to be maintained at a certain rate or level' [23]. It 'requires its own evaluation, apart from and usually after, an evaluation has shown positive results for the programme intervention itself [24]. Sustainability refers not only to the effects of the interventions, but also to whether organizations continue to implement the interventions even after the end of the study period. However, there is no consensus on how sustainability should be defined or measured.

Reviews of the literature on the effectiveness of nonpharmacological interventions for managing pain in older adults have previously been conducted. The authors of these reviews have presented a general picture of how pain in older adults can be managed using appropriate pain assessments, analgesics, and nonpharmacological interventions [25-30]. However, the studies that were included in these reviews were not specifically targeted at community-dwelling older adults $[26,29,30]$. Thus, the reviews lack sufficient information to evaluate and compare the effectiveness of the interventions in reducing pain intensity [25, 29]. Also, they did not discuss the suitability and sustainability of the interventions. The literature reviews also included quasiexperimental studies, pilot studies, case studies, doctoral theses, and unpublished articles [26-29]. Some literature reviews were published from the 1930s to the 2010s, and therefore could not reflect recent innovations, trends, and up-to-date information on pain management for older adults $[27,29,30]$. An appraisal of the quality of the included articles was not performed, and there may also have been some bias in the selection of these articles. Thus, it is difficult to determine the quality of these literature reviews $[25-27,29]$. The authors of the reviews did not adopt guidelines for conducting the literature reviews and presenting the findings [25-30]. Thus, for the present systematic review of nonpharmacological methods of managing pain in community-dwelling older adults, it was essential to identify and appraise the current relevant literature and to provide evidence on the quality of the care delivered to the community-dwelling older adults, as well as to fill in the gaps identified in the previous literature reviews.

This systematic review included articles from 2005 to February 2019, and adopted the Preferred Reporting Items for Systematic Reviews and Meta-Analyses (PRISMA) format to guide the process of searching for articles and writing the report. It is comprised of a $27-$ item checklist and a four-phrase flow diagram to help authors report a wide array of systematic reviews to assess the benefits and harms of a healthcare intervention' [31, 32]. PRISMA can help to ensure that systematic reviews and meta-analyses are reported in a transparent and complete manner, and can guide authors in assessing the strengths and weaknesses of interventions in a systematic review [31]. The present systematic review includes recently published and up-to-date studies on non-pharmacological interventions for managing pain in community-dwelling older adults. Since the participants 
of the studies cannot be reached, the suitability and sustainability of the interventions were assessed by whether the interventions could be carried out by the participants themselves and whether they succeeded in reducing the intensity of their pain.

The research questions were as follows.

1. Are non-pharmacological interventions for managing pain effective at reducing pain intensities in community-dwelling older adults with chronic pain?

2. Are non-pharmacological interventions for pain management suitable for use in communitydwelling older adults with chronic pain?

3. Are non-pharmacological interventions for pain management sustainable in follow-up assessments of community-dwelling older adults with chronic pain?

Therefore, the objective of the present systematic review was to evaluate the effectiveness, suitability, and sustainability of non-pharmacological interventions for managing pain in community-dwelling older adults.

\section{Methods}

\section{Search terms}

To find articles of interest, we identified and modified search terms in consultation with a university faculty librarian with knowledge of the subject area. The following search terms were adopted: ((Pain OR Pain management)) AND (Non-pharmacological interventions) AND ((Old OR Older OR Older people OR Elderly)), (Complementary therapy), ((Non-malignant pain OR Pain management)), and (Community).

\section{Eligibility criteria}

The following inclusion criteria were set for the systematic review.

1. Research studies published from 1 January 2005 to 28 February 2019;

2. Randomized controlled trials;

3. Articles written in English;

4. Trials assessing non-malignant chronic pain as the primary outcome;

5. Trials rating pain by intensity;

6. A non-pharmacological intervention was the sole intervention;

7. The recruited participants were communitydwelling older adults, who were not institutionalized or staying in a nursing home;

8. A criterion for being a participant in the study was being over 65 years of age;
9. The recruited participants did not suffer from any psychiatric illnesses that could affect their understanding of the interventions; and

10. A full text of the article was available.

The following works were excluded from the systematic review.

1. Book reviews;

2. Dissertations;

3. Literature reviews;

4. Study protocols;

5. Pilot studies;

6. Articles examining the effectiveness of commercial products; and

7. Articles examining the intake of traditional Chinese medications.

\section{Information sources}

Five internet-based databases were selected for the literature search: CINHAL, Journals@Ovid, Medline, PsycInfo, and PubMed. These five databases contain medical and nursing journal articles related to pain and pain management. The literature search was conducted in March 2019.

Additional searches using Medical Subject Headings $(\mathrm{MeSH})$ were performed. Medline and PubMed were searched. MeSH terms used in the additional search were chronic pain, complementary therapies, aged, and aged, 80 and over. The search terms were modified in the additional search as MeSH has developed its terminology for searching for information.

\section{Search and study selection}

After we performed the initial search using the search terms in the five databases and the additional search of $\mathrm{MeSH}$ terms in the two databases, we used EndNoteX8 to remove duplicate articles [33]. The articles were then screened by title and abstract to find relevant studies on improving pain conditions and randomized controlled trials. Three independent reviewers who are experienced in conducting pain research undertook the process of screening for relevant articles. A further selection of the remaining articles was achieved by applying the inclusion and exclusion criteria to screen the abstracts and full text of the articles.

\section{Data collection process and data items}

We designed a specific data extraction form for this systematic review. Data were extracted from the selected articles, and were reviewed by three people. Disagreements on whether certain articles should or should not be included were resolved by discussion among the three reviewers until a consensus was reached. The data 
extraction form contained items covering the title of the article, authors, journal, issue, year of publication, and study characteristics, including the aims of the study, study design, study duration, intervention, follow-up assessment, and recruitment procedure. The participants' characteristics were also extracted, including the number of recruited participants, their mean age, gender, and ethnicity. Primary and secondary outcome measures were also recorded, along with the relevant assessment tools, the main findings of the studies, and the limitations.

\section{Suitability and sustainability of the non-pharmacological interventions}

To examine the suitability and sustainability of the nonpharmacological interventions, we focused on the personnel required to deliver the interventions and the pain reduction effect. First, we looked at whether the interventions could be carried out by the participants individually or whether they had to be delivered by a therapist, healthcare professional, or a third person. Second, the sustained pain reduction effects of the interventions were explored by looking at the level of pain intensity in the follow-up assessment. The above information was noted down on the data extraction form for analysis.

\section{Quality appraisal}

A quality appraisal was conducted using the Jadad Scale, which was developed to assess the quality of the articles in a systematic review by avoiding selection bias and examining the effect of blinding in randomized controlled trials [34]. There are five criteria in the Jadad Scale, including randomization (randomized study design and appropriateness of randomization), blinding (double-blind and appropriateness of and blinding method, and description of withdrawals and dropouts were described. Each criterion is assigned a score of one point, for a total score of five. A higher score indicates a higher quality study. In this review, an interrater consistency of 0.66 in the Jadad Scale was found [34]. Disagreements were discussed among the three reviewers and resolved.

\section{Summary measures}

The primary outcome measure of the systematic review was a reduction in the mean intensity of pain in community-dwelling older adults after the use of nonpharmacological interventions in the studies. The mean intensity had to be presented in a numerical format, regardless of which assessment tools were adopted. The pre-intervention mean pain intensity was compared to the post-intervention mean pain intensity to determine whether there had been any improvement. Different pain assessment tools were used in the included articles. To make comparisons about the pain intensity in different studies, pain intensity levels were converted to a numeric rating scale ranging from zero to ten, with zero indicating no pain and ten representing the worst pain.

\section{Results \\ Study selection}

The initial search of the five internet-based databases yielded 8232 articles. After the removal of duplicates, 3662 articles remained. The titles and abstracts of the articles were then screened to identify studies related to pain, resulting in 233 articles. Ultimately, we retrieved ten articles that met the criteria for inclusion in this review. The PRISMA checklist (see 'Additional file 1') shows the reporting process, and the flow diagram in Fig. 1 illustrates the study selection process.

\section{Study characteristics}

The articles included in the systematic review were categorized by type of intervention. Ten articles were included. There was article on acupressure and one on guided imagery. There were two articles each on acupressure, qigong, periosteal stimulation, and Tai Chi.

The duration of the included studies ranged from 4 weeks to 4 months. Apart from the pre-assessment and immediate post-intervention assessment, most of the studies included a follow-up assessment after the completion of the intervention. The earliest follow-up assessment was found to be 3 weeks after the last intervention. Table 1 shows details of the characteristics of the studies.

\section{Quality appraisal}

All of the studies described themselves as randomized controlled trials and seven articles presented their methods of randomization. Only Itoh et al.'s study of acupuncture and Li et al.'s study of acupressure were described as double-blinded studies and included details of the method of double blinding [35, 36]. Seven researchers gave details of the withdrawals and dropouts, including the reasons for them. The studies generated scores ranging from two to five out of five points. Table 2 shows the results of the quality appraisal.

\section{Results of the included studies}

\section{Demographics of the participants and pain assessment tools}

There were no significant differences in the demographic data of the intervention and control groups in any of the included studies. The number of recruited participants ranged from 26 to 221 . The mean age of the participants ranged from 66.75 to 76 years. Three studies did not record the use of medications by the participants 


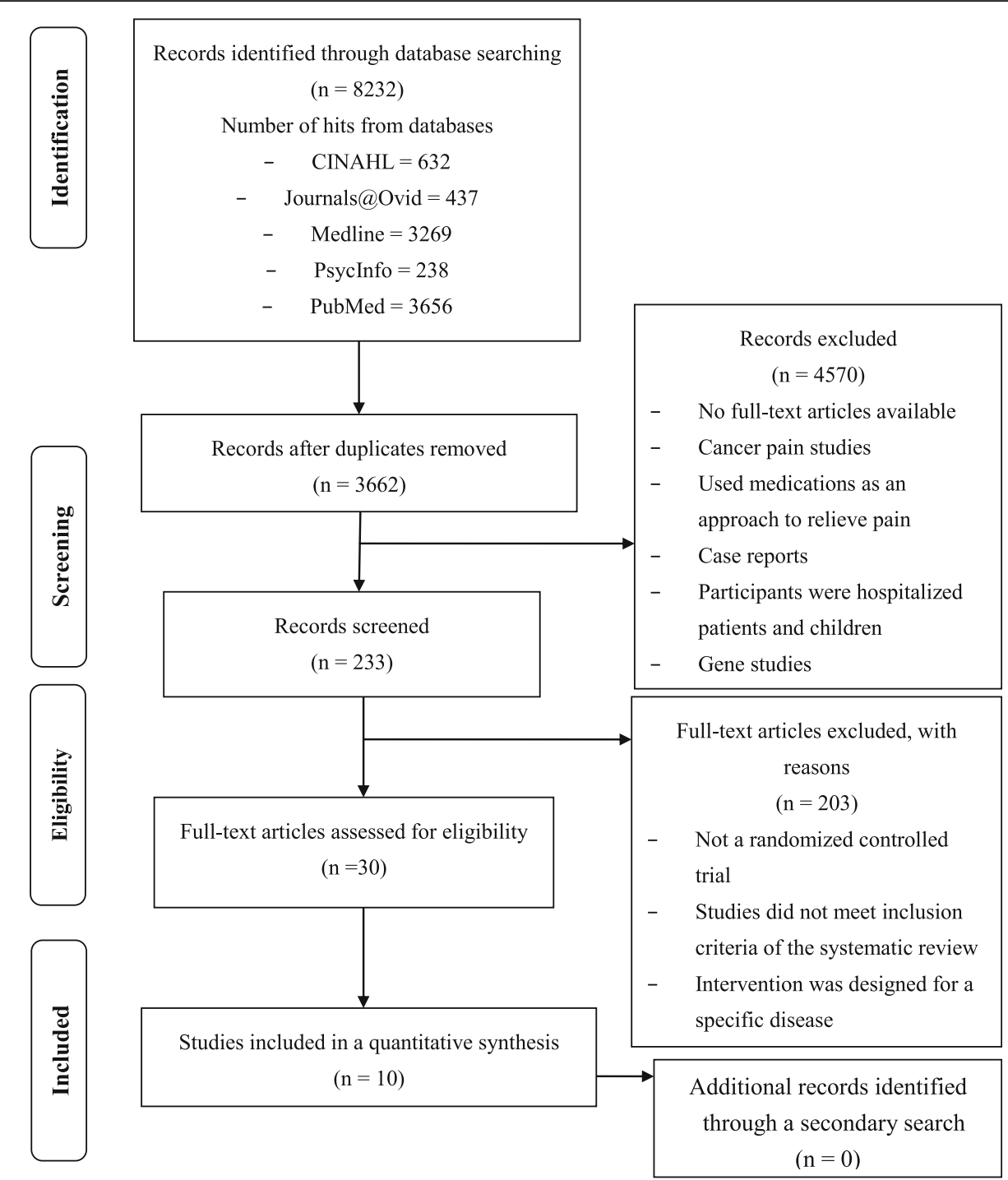

Fig. 1 Flow diagram of the study selection process

[35, 41, 43]. The studies adopted different pain rating scales. Commonly used scales included the visual analogue scale, numeric rating scales, and the Western Ontario and McMaster University Osteoarthritis Index (WOMAC).

\section{Non-pharmacological interventions that were included and their effectiveness}

All of the studies demonstrated the effectiveness of nonpharmacological interventions for reducing pain in community-dwelling older adults, as demonstrated by decreases in pain intensity from a comparison of the baseline and post-intervention data. Pain intensity data were converted into numeric scores for comparisons between studies, and are shown in Additional file 2: Table S1. The studies covered the interventions of acupressure, acupuncture, guided imagery, periosteal stimulation, qigong, and Tai Chi [35-44]. The net change in pain intensity in the intervention group in the post-intervention assessment ranged from -3.13 to -0.65 after the conversion. However, although improvements in pain intensity were found, statistically significant reductions in pain intensity were not found in all of the studies. No statistically significant reductions in pain intensity were found in the studies of White et al., Baird et al., Weiner et al., and von Trott et al. [37-40]. The studies of $\mathrm{Li}$ et al., Itoh et al., Yang et al., Brismee et al., Fransen et al., and Weiner et al. reported a statistically significant reduction of $p<.01$ or $p<.05$ [35, 36, 41-44].

\section{Suitability and sustainability of the included studies}

After the study period, the older adults could continue to implement some of the non-pharmacological interventions. In the study, the older adults were taught to 
Table 1 Aims and Study Designs of the Included Articles

\begin{tabular}{|c|c|c|c|c|}
\hline Reference & Country & Aims & Duration and intervention & $\begin{array}{l}\text { Follow-up } \\
\text { assessment }\end{array}$ \\
\hline \multicolumn{5}{|l|}{ Acupressure } \\
\hline $\begin{array}{l}\text { Li et al., } \\
2018[35]\end{array}$ & $\begin{array}{l}\text { United } \\
\text { States }\end{array}$ & $\begin{array}{l}\text { To investigate the efficacy of a self-administered acu- } \\
\text { pressure treatment on older adults with knee } \\
\text { osteoarthritis }\end{array}$ & $\begin{array}{l}8 \text { weeks } \\
3 \text { visits to the centre in } 8 \text { weeks } \\
\text { - Acupressure was taught to the participants and } \\
\text { applied once daily for } 5 \text { days in the study period } \\
\text { Weekly phone calls }\end{array}$ & None \\
\hline \multicolumn{5}{|l|}{ Acupuncture } \\
\hline $\begin{array}{l}\text { Itoh et al., } \\
2006 \text { [36] }\end{array}$ & Japan & $\begin{array}{l}\text { To examine the effectiveness of real acupuncture to } \\
\text { trigger points as a treatment for chronic low back } \\
\text { pain }\end{array}$ & $\begin{array}{l}12 \text { weeks } \\
2 \text { interventions in } 3 \text { weekly sessions, with a washout } \\
\text { period of } 3 \text { weeks: } \\
\text { - Trigger point acupuncture }\end{array}$ & 3 weeks \\
\hline $\begin{array}{l}\text { White } \\
\text { et al., } \\
2012 \text { [37] }\end{array}$ & $\begin{array}{l}\text { United } \\
\text { Kingdom }\end{array}$ & $\begin{array}{l}\text { To examine if an enhanced nonspecific effect } \\
\text { associated with needling is present, to determine the } \\
\text { effects of the consultation process and the } \\
\text { practitioner, to investigate the efficacy of acupuncture } \\
\text { on severe osteoarthritis pain, and to improve } \\
\text { interpretation of the quantitative study through a } \\
\text { nested qualitative network }\end{array}$ & $\begin{array}{l}8 \text { weeks } \\
\text { Intervention twice per week for } 4 \text { weeks, with } 2 \\
\text { consultations and face-to-face open-ended narrative } \\
\text { qualitative interviews as a follow-up assessment }\end{array}$ & $\begin{array}{l}4 \text { to } 8 \\
\text { weeks }\end{array}$ \\
\hline \multicolumn{5}{|c|}{ Guided imagery } \\
\hline $\begin{array}{l}\text { Baird, } \\
\text { Murawski, } \\
\& \text { Wu, } \\
2010[38]\end{array}$ & USA & $\begin{array}{l}\text { To investigate the efficacy of guided imagery with } \\
\text { relaxation (GIR) on symptom relief and medication } \\
\text { use in osteoarthritis patients compared with a sham } \\
\text { intervention of planned relaxation }\end{array}$ & $\begin{array}{l}16 \text { weeks } \\
12 \text {-min audiotape-guided GIR twice a day }\end{array}$ & None \\
\hline \multicolumn{5}{|c|}{ Periosteal stimulation (PST) } \\
\hline $\begin{array}{l}\text { Weiner } \\
\text { et al., } \\
2007[39]\end{array}$ & USA & $\begin{array}{l}\text { To evaluate the efficacy of PST in pain reduction and } \\
\text { improved function in older adults with knee } \\
\text { osteoarthritis, including those with advanced disease }\end{array}$ & $\begin{array}{l}6 \text { weeks } \\
\text { 30-min session once per week for PST }\end{array}$ & 12 weeks \\
\hline $\begin{array}{l}\text { Weiner } \\
\text { et al., } \\
2008[44]\end{array}$ & USA & $\begin{array}{l}\text { To evaluate the effect of percutaneous electrical nerve } \\
\text { stimulation (PENS) with and without general } \\
\text { conditioning and aerobic exercise (GCAE) on } \\
\text { decreasing pain and enhancing function in older } \\
\text { adults with chronic low back pain }\end{array}$ & $\begin{array}{l}6 \text { weeks } \\
\text { Twice per week } \\
2 \text { groups: } \\
\text { - PENS } \\
\text { - PENS and GCAE }\end{array}$ & 24 weeks \\
\hline \multicolumn{5}{|l|}{ Qigong } \\
\hline $\begin{array}{l}\text { von Trott } \\
\text { et al., } \\
2009[40]\end{array}$ & Germany & $\begin{array}{l}\text { To examine if qigong is more effective than no } \\
\text { intervention (waiting list) and exercise therapy in } \\
\text { older patients with chronic neck pain }\end{array}$ & $\begin{array}{l}12 \text { weeks } \\
24 \text { sessions ( } 45 \text { min each), } 2 \text { sessions per week: } \\
\text { - Qigong } \\
\text { - Exercise therapy }\end{array}$ & 24 weeks \\
\hline $\begin{array}{l}\text { Yang } \\
\text { et al., } \\
2005[41]\end{array}$ & Korea & $\begin{array}{l}\text { To evaluate the short-term and residual effects of Qi- } \\
\text { therapy on chronic pain and mood in older adults }\end{array}$ & $\begin{array}{l}4 \text { weeks } \\
20 \text { min per session, twice per week: } \\
\text { External Korean Qi-therapy }\end{array}$ & 2 weeks \\
\hline \multicolumn{5}{|l|}{ Tai chi } \\
\hline $\begin{array}{l}\text { Brismee } \\
\text { et al., } \\
2007 \text { [42] }\end{array}$ & USA & $\begin{array}{l}\text { To examine the effects of group and home video Tai } \\
\text { Chi exercise intervention programmes } \\
\text { To evaluate the sustainability of the effects of Tai Chi } \\
\text { on osteoarthritis after cessation of the exercise } \\
\text { intervention } \\
\text { To incorporate measurements taken at intermediate } \\
\text { time points to evaluate and compare them with the } \\
\text { pre- and post-measurements in previous studies } \\
\text { To apply a standardized form of Tai Chi exercise that } \\
\text { has been most widely used in published longitudinal } \\
\text { Tai Chi studies for various health conditions }\end{array}$ & $\begin{array}{l}12 \text { weeks } \\
\text { Tai Chi exercise programme (24-form simplified Yang- } \\
\text { style Tai Chi), 6-week group Tai Chi, } 3 \text { 40-min sessions } \\
\text { per week, another 6-week home Tai Chi programme }\end{array}$ & 6 weeks \\
\hline $\begin{array}{l}\text { Fransen } \\
\text { et al., } \\
2007 \text { [43] }\end{array}$ & Australia & $\begin{array}{l}\text { To test whether hydrotherapy or Tai Chi classes are } \\
\text { accepted by patients with chronic symptomatic } \\
\text { osteoarthritis of the hips or knees as physical activity } \\
\text { options that can provide measurable improvements } \\
\text { in joint pain and physical function }\end{array}$ & $\begin{array}{l}12 \text { weeks } \\
\text { 1-h class twice a week: } \\
\text { - Hydrotherapy programme } \\
\text { - Tai Chi: modification of } 24 \text { forms from the Sun style } \\
\text { of Tai Chi }\end{array}$ & 24 weeks \\
\hline
\end{tabular}


Table 2 Quality Appraisal of the Included Studies

\begin{tabular}{|c|c|c|c|c|c|c|}
\hline Reference & $\begin{array}{l}\text { Described as } \\
\text { randomized }\end{array}$ & $\begin{array}{l}\text { Appropriate } \\
\text { randomization }\end{array}$ & $\begin{array}{l}\text { Described as } \\
\text { double blinded }\end{array}$ & $\begin{array}{l}\text { Appropriate double } \\
\text { blinding method }\end{array}$ & $\begin{array}{l}\text { Described withdrawals } \\
\text { and dropouts }\end{array}$ & $\begin{array}{l}\text { Total }(5 \\
\text { points) }\end{array}$ \\
\hline \multicolumn{7}{|l|}{ Acupressure } \\
\hline Li et al., 2018 [35] & $\checkmark$ & $\checkmark$ & $\checkmark$ & $\checkmark$ & $\checkmark$ & 5 \\
\hline \multicolumn{7}{|l|}{ Acupuncture } \\
\hline Itoh et al., 2006 [36] & $\checkmark$ & $\checkmark$ & $\checkmark$ & $\checkmark$ & $\checkmark$ & 5 \\
\hline $\begin{array}{l}\text { White et al., } 2012 \\
\text { [37] }\end{array}$ & $\checkmark$ & $\checkmark$ & $x$ & NA & $\checkmark$ & 3 \\
\hline \multicolumn{7}{|l|}{ Guided imagery } \\
\hline $\begin{array}{l}\text { Baird, Murawski, \& } \\
\text { Wu, } 2010 \text { [38] }\end{array}$ & $\checkmark$ & $\checkmark$ & $x$ & NA & $x$ & 2 \\
\hline \multicolumn{7}{|l|}{ Periosteal stimulation (PST) } \\
\hline $\begin{array}{l}\text { Weiner et al., } 2007 \\
\text { [39] }\end{array}$ & $\checkmark$ & $x$ & $x$ & NA & $\checkmark$ & 2 \\
\hline $\begin{array}{l}\text { Weiner et al., } 2008 \\
\text { [44] }\end{array}$ & $\checkmark$ & $\checkmark$ & $x$ & NA & $\checkmark$ & 3 \\
\hline \multicolumn{7}{|l|}{ Qigong } \\
\hline $\begin{array}{l}\text { von Trott et al., } 2009 \\
\text { [40] }\end{array}$ & $\checkmark$ & $\checkmark$ & $x$ & NA & $x$ & 2 \\
\hline Yang et al., 2005 [41] & $\checkmark$ & $x$ & $x$ & NA & $x$ & \\
\hline \multicolumn{7}{|l|}{ Tai chi } \\
\hline $\begin{array}{l}\text { Brismee et al., } 2007 \\
\text { [42] }\end{array}$ & $\checkmark$ & $\checkmark$ & $x$ & NA & $\checkmark$ & 3 \\
\hline $\begin{array}{l}\text { Fransen et al., } 2007 \\
\text { [43] }\end{array}$ & $\checkmark$ & $\checkmark$ & $x$ & NA & $\checkmark$ & 3 \\
\hline
\end{tabular}

perform the following interventions by themselves: acupressure, guided imaginary, qigong, and Tai Chi $[35,38$, 40-43]. Acupuncture and periosteal stimulation required a therapist to perform the intervention. With regard to the sustainability of the interventions, statistically significant decreases in pain intensity in the follow-up assessment were demonstrated in the studies on acupuncture, periosteal stimulation, qigong, and Tai Chi [36, 39-44]. No follow-up assessment was conducted in the studies on acupressure, acupuncture, and guided imagery [35, 37, 38]. Details of the results are presented in Additional file 2: Table S1.

\section{Discussion}

\section{Summary of evidence}

Effectiveness of non-pharmacological pain management in community-dwelling older adults

The included non-pharmacological interventions worked well in the older adults in that they had an immediate pain-relieving effect. The pain intensities of the participants in the intervention groups decreased significantly in most of the interventions, for example, the acupressure, qigong, Tai Chi, and hydrotherapy interventions $[35,40,43]$. The other non-pharmacological interventions led to a reduction in pain intensity in the older adults, although without statistical significance. The older adults benefitted directly from lower pain intensity and possibly from a better quality of life, such as through enhancements in mobility and in their ability to carry out the activities of daily living. However, no conclusion can be drawn about which interventions offer the best pain reduction effect in community-dwelling older adults. Further research to compare interventions is recommended to determine the duration of the reduction in pain and the best interventions for decreasing pain in community-dwelling older adults, and to explore the clinical significance of the non-pharmacological interventions.

\section{Suitability of non-pharmacological pain management in community-dwelling older adults}

It is essential to equip community-dwelling older adults with adequate self-help skills and techniques to manage chronic disease. As pain is present in 25 to $50 \%$ of community-dwelling older adults, providing them pain with management skills may be one of the solutions to promoting better health and quality of life [2].

Some of the included articles indicated that certain interventions can be continuously implemented by the older adults themselves. These interventions were acupressure, guided imagery, qigong, and Tai Chi. Satisfactory reductions in pain intensity immediately after the 
interventions were shown in these studies [35, 38, 4043]. The studies showed that the pain reduction effects were maintained in the follow-up assessment, with participant dropout rates of 3 to 24\% [40-43]. The older adults were able to practise the interventions when they were in pain. The interventions became treatment options that were available to them at all times, and they had the ability to perform these interventions themselves. This is in alignment with the concept of selfmanagement held by the older adults.

\section{Sustainability of non-pharmacological pain management in community-dwelling older adults}

The sustainability of the interventions refers to whether the participants can self-administer the interventions and maintain the pain reduction effect after the study period. Acupuncture and periosteal stimulation resulted in significant reductions in pain [36, 37, 39, 44]. However, the highest level of decrease in pain was sustained only immediately or for a short time during the postintervention period. In other words, the interventions need to be delivered on a regular basis to promote the sustainability of the pain reduction. Also, older adults cannot implement these interventions by themselves because an acupuncturist is required to perform them. As a result, older adults can only learn about the concepts and benefits of the interventions, but cannot implement the interventions by themselves whenever they are in pain. Thus, the application of these particular interventions is limited. Another concern is whether the older adults have the ability to continue to self-apply the nonpharmacological interventions. Even though the interventions are suitable for older adults and they were taught the relevant self-application method, their cognitive function and ability to continue using the method remains in question. Their ability to follow the application guidelines and the dosage of the intervention may need to be monitored by a nurse or caregiver. Therefore, it is recommended that the caregiver of an older adult, such as a family member, learn and perform the intervention in order to ensure its effectiveness and safety.

The immediate and short-term effects of pain reduction were shown in the included non-pharmacological pain management studies. However, further investigations are needed to determine the long-term effectiveness of the interventions in managing pain.

\section{Strengths}

The review identified effective non-pharmacological interventions for managing chronic pain that were suitable and sustainable for community-dwelling older adults. Articles from the most recent 10 years were retrieved. PRISMA was adopted to guide the systematic review process. The systematic review provides ideas to nurses about the use of non-pharmacological methods of managing pain in older adults.

\section{Limitations}

The present systematic review has some limitations. A limited number of relevant articles were found in the review. It is possible that the combinations of search terms used resulted in inadequate coverage of the relevant articles. Also, the aim of the systematic review was to examine the effectiveness of nonpharmacological interventions for managing pain. Diverse interventions were included, and there was no in-depth investigation of individual interventions. In addition, no measurement was used to assess the suitability of the interventions used by the older adults. Only articles with pain intensity as the primary outcome were included. It is likely that the review failed to identify studies measuring pain as a secondary outcome in which pain may also have been reduced. The pain intensities in the studies were not standardized. Community-dwelling older adults comprised the population in the systematic review, and the results cannot be generalized to other populations. Only articles in the electronic databases that were published in English were included in the search. Therefore, the analysis in the review may be incomplete, as articles published in other languages have not been studied.

\section{Conclusions}

Ten articles were included in the systematic review. Acupressure, acupuncture, guided imagery, qigong, periosteal stimulation, and Tai Chi were identified as non-pharmacological interventions that provided adequate pain management for community-dwelling older adults, were suitable for them to use, and had sustainable pain reduction effects. Effectiveness, suitability and sustainability should be elements that researchers take into consideration when they design a non-pharmacological intervention for pain management. These definitely can help to further reduce the intensity of the pain felt by older adults and improve their health, making it possible for them to stay in the community. One concern, however, was how to maximize the effects of pain management and maintain the sustainability of the pain reductions. In planning future studies on this topic, we suggest that researchers focus on equipping community-dwelling older adults with the skills that they need to improve their self-efficacy in managing pain, taking into consideration their cognitive function and ability to perform the non-pharmacological pain management interventions, rather than solely investigating the effectiveness of such interventions. 


\section{Supplementary information}

Supplementary information accompanies this paper at https://doi.org/10. 1186/s12889-019-7831-9.

Additional file 1. PRISMA 2009 checklist. This was the PRISMA checklist used to report the systematic review.

Additional file 2: Table S1. Results of the Included Studies.

\section{Abbreviations}

MeSH: Medical Subject Headings; MPQ: McGill Pain Questionnaire; NRS: Numeric rating scale; PRISMA: Preferred Reporting Items for Systematic Reviews and Meta-Analyses; SF-MPQ: The short-form McGill Pain Questionnaire; VAS: Visual analogue scale; WOMAC: Western Ontario and McMaster Universities osteoarthritis index

\section{Acknowledgements}

Not applicable.

\section{Authors' contributions}

All of the authors contributed to the design of the study. TSK drafted the manuscript. MT, LSF, and TF supervised and provided advice on the manuscript. All authors read and approved the final manuscript

\section{Funding}

This review was conducted with no external and internal funding.

\section{Availability of data and materials}

The datasets used and/or analysed during this study are available from the corresponding author on reasonable request.

\section{Ethics approval and consent to participate}

Not applicable.

\section{Consent for publication}

Not applicable.

\section{Competing interests}

The authors declare that they have no competing interests.

\section{Author details}

'School of Nursing, The Hong Kong Polytechnic University, Kowloon, Hong Kong. 'School of Health Sciences, University of Brighton, Westlain House, Village Way, Brighton BN1 9PH, UK

\section{Received: 1 April 2019 Accepted: 22 October 2019}

Published online: 08 November 2019

\section{References}

1. International Association for the Study of Pain. IASP Taxonomy - IASP: International Association for the Study of Pain. 2014. http://www.iasp-pain org/Education/Content.aspx? ItemNumber=1698\&navitemNumber= 576\#Pain. Accessed 11 Aug 2014.

2. Brochet B, Michel P, Barberger-Gateau P, Dartigues JF. Population-based study of pain in elderly people: a descriptive survey. Age Ageing. 1998;27: 279-84

3. Chung JWY Wong TKS. Prevalence of pain in a community population. Pain Med. 2007;8:235-42.

4. International Association for the Study of Pain. Classification of chronic pain, second edition (revised) https://www.iasp-pain.org/PublicationsNews/ Content.aspx?ltemNumber=1673\&navltemNumber=677; 2012. Accessed 12 Aug 2014

5. Fouladbakhsh JM, Szczesny S, Jenuwine ES, Vallerand AH. Nondrug therapies for pain management among rural older adults. Pain Manag Nurs. 2011;12:70-81.

6. Brown ST, Kirkpatric ML, Swanson MS, McKenzie IL. Pain experience of the elderly. Pain Manag Nurs. 2011;12:190-6.

7. $\mathrm{Ng} J \mathrm{KF}$, Tsui SL, Chan WS. Prevalence of common chronic pain in Hong Kong adults. Clin J Pain. 2002;18:275-81.
8. Tse MMY, Wan VTK, Ho SSK. Profile of pain and use of pharmacological and non-pharmacological methods for relieving pain in older persons in nursing homes. J Pain Manag. 2010;3:1-13.

9. American Geriatrics Society Panel on Persistent Pain in Older Persons. The management of persistent pain in older persons. J Am Geriatr Soc. 2002;5 S205-24.

10. Fine PG. Chronic pain management in older adults: special considerations. J Pain Symptom Manag. 2009;38:S4-S14.

11. Stringer J. Basic concepts in pharmacology: what you need to know for each drug class. 4th ed; 2011. https://doi.org/10.1345/aph.1Q304.

12. Reid MC, Eccleston C, Pillemer K. Management of chronic pain in older adults. BMJ. 2015;350:h532

13. Cusack BJ. Pharmacokinectics in older persons. Am J Geriatr Pharmacother. 2004;2:274-302

14. Cavalieri TA. Management of pain in older adults. J Am Osteopath Assoc. 2005;105:S12-7

15. Prohaska TR, Keller ML, Leventhal EA, Leventhal L. Impact of symptoms and aging attribution on emotions and coping. Health Psychol. 1987;6:495-514.

16. Breivik H, Borchgrevink PC, Allen SM, et al. Assessment of pain. Br J Anaesth. 2008;101:17-24

17. Schofield P. The assessment of pain in older people: UK national guidelines. Age Ageing. 2018;47:11-i22.

18. Schofield P, Abdulla A. Pain assessment in the older population: what the literature says. Age Ageing. 2018;47:324-7.

19. Oxford University Press. Suitability. 2019. https://en.oxforddictionaries.com/ definition/suitability; Accessed 2 March 2019.

20. De La Montana J, Miguez M. Suitability of the short-form mini nutritional assessment in free-living elderly people in the northwest of Spain. J Nutr Health Aging. 2011;15:187-91.

21. Hwang HF, Liang WM, Chiu YN, Lin MR. Suitability of the WHOQOL-BREF for community-dwelling older people in Taiwan. Age Ageing. 2003;32:593-600.

22. Ward L, Treharne GJ, Stebbings S. The suitability of yoga as a potential therapeutic intervention for rheumatoid arthritis: a focus group approach. Musculoskeletal Care. 2011:9:211-21.

23. Oxford University Press. Sustainability. 2019. https://en.oxforddictionaries com/definition/sustainability; Accessed 2 Mar 2019.

24. Scheirer MA. Is sustainability possible? A review and commentary on empirical studies of program sustainability. Am J Eval. 2005;26:320-47.

25. Bruckenthal P, Marino MA, Snelling L. Complementary and integrative therapies for persistent pain management in older adults: a review. J Gerontol Nurs. 2016:42:41-8.

26. Hokka M, Kaakinen P, Polkki T. A systematic review: non-pharmacological interventions in treating pain in patients with advanced cancer. J Adv Nurs. 2014;70:1954-69.

27. Lunde LH, Nordhus $\mathrm{H}$, Pallesen S. The effectiveness of cognitive and behavioural treatment of chronic pain in the elderly: a quantitative review. J Clin Psychol Med Settings. 2009;16:254-62.

28. Park J, Hughes AK. Nonpharmacological approaches to the management of chronic pain in community-dwelling older adults: a review of empirical evidence. J Am Geriatr Soc. 2012;60:555-68.

29. Schofield P, Reid D. The assessment and management of pain in older people: a systematic review. Int J Disabil Hum Dev. 2006;5:9-16.

30. Sindhu F. Are non-pharmacological nursing interventions for the management of pain effective? A meta-analysis. J Adv Nurs. 1996;24:1152-9.

31. Liberati A, Altman DG, Tetzlaff J, et al. The PRISMA statement for reporting systematic reviews and meta-analyses of studies that evaluate healthcare interventions: explanation and elaboration. BMJ. 2009:339:b2700.

32. Moher D, Liberati A, Tetzlaff J, Altman DG, The PRISMA group. Preferred Reporting Items for Systematic Reviews and Meta-Analyses: The PRISMA statement. PLoS Med. 2009;6:e1000097.

33. Clarivate Analytics. The little EndNote how-to book. 2017. http://clarivate. libguides.com/ld.php?content_id=34717450; Accessed 27 July 2019.

34. Jadad AR, Moore A, Carroll D, et al. Assessing the quality of reports or randomized clinical trials: is blinding necessary? Control Clin Trials. 1996;17:1-12

35. Li LW, Harris RE, Tsodikov A, Struble L, Murphy S. Self-acupressure for older adults with symptomatic knee osteoarthritis: a randomized controlled trial. Arthritis Care Res. 2018:70:211-9.

36. Itoh K, Katsumi Y, Hirota S, Kitakoji H. Effects of trigger point acupuncture on chronic low back pain in elderly patients--a sham-controlled randomised trial. Acupunct Med. 2006;24:5-12. 
37. White P, Bishop FL, Prescott P, Scott C, Little P, Lewith G. Practice, practitioner, or placebo? A multifactorial, mixed-methods randomized controlled trial of acupuncture. Pain. 2012;153:455-62.

38. Baird CL, Murawski MM, Wu J. Efficacy of guided imagery with relaxation for osteoarthritis symptoms and medication intake. Pain Manag Nurs. 2010;11:56-65.

39. Weiner DK, Rudy TE, Morone N, Glick R, Kwoh CK. Efficacy of periosteal stimulation therapy for the treatment of osteoarthritis-associated chronic knee pain: an initial controlled clinical trial. J Am Geriatr Soc. 2007;55:1541-7.

40. von Trott P, Wiedemann AM, Ludtke R, Reishauer A, Willich SN, Witt CM. Qigong and exercise therapy for elderly patients with chronic neck pain (QIBANE): a randomized controlled study. J Pain. 2009;10:501-8.

41. Yang KH, Kim YH, Lee MS. Efficacy of qi-therapy (external qigong) for elderly people with chronic pain. Int J Neurosci. 2005;1 15:949-63.

42. Brismee JM, Paige RL, Chyu MC, et al. Group and home-based tai chi in elderly subjects with knee osteoarthritis: a randomized controlled trial. Clin Rehabil. 2007;21:99-111.

43. Fransen M, Nairn L, Winstanley J, Lam P, Edmonds J. Physical activity for osteoarthritis management: a randomized controlled clinical trial evaluating hydrotherapy or tai chi classes. Arthritis Rheum. 2007:57:407-14.

44. Weiner DK, Perera S, Rudy TE, et al. Efficacy of percutaneous electrical nerve stimulation and therapeutic exercise for older adults with chronic low back pain: a randomized controlled trial. Pain. 2008:140:344-57.

\section{Publisher's Note}

Springer Nature remains neutral with regard to jurisdictional claims in published maps and institutional affiliations.

Ready to submit your research? Choose BMC and benefit from:

- fast, convenient online submission

- thorough peer review by experienced researchers in your field

- rapid publication on acceptance

- support for research data, including large and complex data types

- gold Open Access which fosters wider collaboration and increased citations

- maximum visibility for your research: over $100 \mathrm{M}$ website views per year

At $\mathrm{BMC}$, research is always in progress.

Learn more biomedcentral.com/submissions 